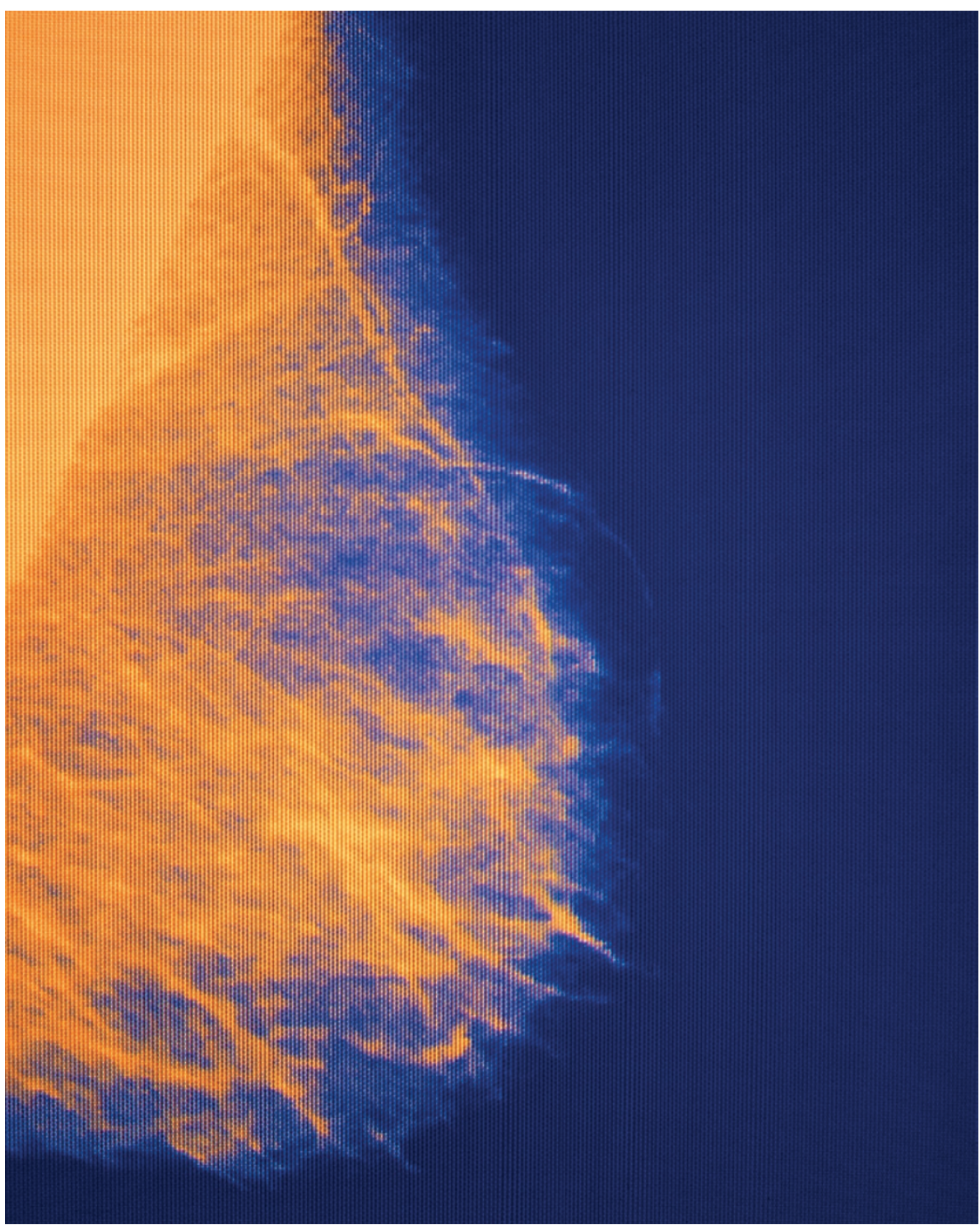

Mammography is used to examine the soft tissues of the breast in order to screen women for cancer.

SCREENING

\title{
Don't look now
}

\section{Mammogram screenings are an established part of women's health care, but are they more trouble than they are worth?}

\section{BY EMILY SOHN}

$\mathrm{B}$ ack in 1980, Canadian researchers decided to tackle a pressing question: how many women could be saved with breast-cancer screening? At the time, many researchers suspected that the relatively new technology could prevent breast-cancer deaths by detecting tumours before they had a chance to grow. The truth proved to be complicated so complicated that researchers are still trying to understand it 35 years later. thought, 'if we wait another two years, maybe a benefit will begin to emerge," she says. "After 25 years, it still hasn't emerged."

Health campaigns often give women a simple message: mammograms save lives. But the data behind that message is so murky that experts continue to disagree about who really needs to be screened. Various organizations offer clashing recommendations that range from the American College of Obstetricians and Gynecologists suggesting that regular mammograms should start at age 40 to the Swiss Medical Board proposing the elimination of routine screening altogether. At the same time, scientists continue to sort through the data from multiple trials, enlist the power of computer models, conduct epidemiological analyses, and take a closer look at the physical and emotional tolls of cancer treatments to address a vexing problem: are mammograms helping women, or hurting them?

\section{INVADER DETECTION}

Decades after it started, the Canadian trial illustrates the essence of the mammography conflict - overall, women who were tested did not live longer, even though screening did uncover many cases of invasive cancer. Those diagnoses set off rounds of chemotherapy, radiation and surgery. But some of the women were already too sick to save, and others had cancers that could have been ignored: the authors estimated that $22 \%$ of the invasive cancers detected by mammograms were unlikely to affect a woman's health, a phenomenon known as overdiagnosis.

The Canadian trial is not the final word, however, and other studies have suggested that widespread screening with mammograms may reduce the overall death rate from breast cancer, although by how much is another question that scientists continue to debate. One review of the literature concluded that mammograms can reduce deaths by $20 \%$ (ref. 2), whereas another that looked at 7 randomized trials put the number at $10-15 \%$ (ref. 3).

After systematically reviewing studies that compared similar groups of women who received different rates of screening, a team led by Russell Harris, an epidemiologist and cancerprevention researcher at the University of North Carolina School of Medicine in Chapel Hill, and his colleagues estimated that regular screening for women between the ages of 50 and 69 could reduce the death rate by about $10 \%$ (ref. 4 ). The benefits are smaller for women in their 40s, Harris says, because the cancer is less common.

For many women, the chance to reduce their risk of dying from breast cancer, even by a small amount, with a fairly simple procedure makes mammography seem worthwhile. But there are reasons to be cautious, says $\mathrm{H}$. Gilbert Welch, an internist at the Geisel School of Medicine at Dartmouth in Hanover, New Hampshire. What a $20 \%$ benefit actually adds up to is a reduction from 5 deaths out of 1,000 women over a 10 -year period to 4 deaths. 
Proving that mammograms, along with other screening tests, extend lives has been notoriously difficult, Welch adds. One reason is that randomized trials - the gold-standard for assessing any kind of medical procedure - need to follow tens of thousands of people for many years, often requiring "heroic efforts" to keep tabs on mostly healthy people, he says. Among other challenges, it is hard to standardize the procedure. Results vary depending on who is reading the images, how hard they look for tumours and what kind of abnormalities get flagged for a call-back.

As trials have marched on over the decades, the landscape of breast cancer has shifted. A rising awareness makes women much more likely to detect lumps and get them checked out without the need for mammograms. Meanwhile, new, targeted treatments allow oncologists to extend the lives of women with advanced cancers who would have died owing to lack of options when trials began. "As we become better able to treat advanced stages of breast cancer," Welch says, "it becomes less important to find early forms of it."

\section{TOO MUCH KNOWLEDGE}

Determining the value of mammograms must take into account the problem of overdiagnosis. Peter Gøtzsche, director of the Nordic Cochrane Centre in Copenhagen, and author of Mammography Screening: Truth, Lies and Controversy (CDC, 2012), led a study that suggested that one-third of Danish women are overdiagnosed ${ }^{5}$. In other countries, including the United Kingdom, Australia and Sweden, the overdiagnosis rate as a result of introducing screening programmes is suggested to be in excess of $50 \%$ (ref. 3 ).

But not everyone agrees that too many women are being screened. Etta Pisano, a radiologist at the Medical University of South Carolina in Charleston, argues that the real problem is over-treatment that occurs after the mammogram. She compares mammograms to metal detectors at airports. Security personnel want to take a close look at anything that looks remotely suspicious because they "want to find all the guns," she says. But when the 'guns' are tumours, which can behave unpredictably, the path forward remains a judgement call.

One major problem, Welch suspects, is that technological improvements (see 'Fewer places to hide') have given screening tests the power to detect more small and slow-growing cancers - twice as many in 2008 as in 1976, according to one study ${ }^{6}$. But the tests are still not finding more of the early stages of aggressive, fast-growing and lethal tumours that often appear between mammograms. If routine screening tests were catching the worst cancers early, Welch says, the data should show progressively fewer late-stage diagnoses as the number of early-stage diagnoses goes up, along with a reduction in death rates. But when he and his colleagues looked at data on 16-million

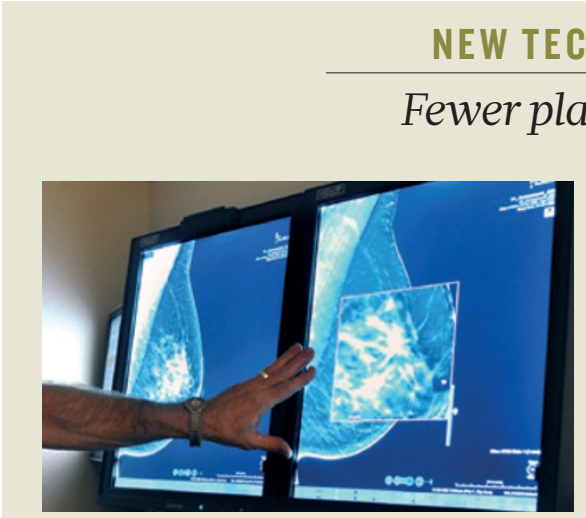

Mammograms are not the only way to screen for breast cancer. Ultrasound and magnetic resonance imaging have been available for years, particularly for women at high-risk of the disease. And a wide range of new technologies is making ever-smaller tumours increasingly easy to spot.

Tomosynthesis (pictured) takes X-ray slices of the breast to create a 3D image. According to a 2014 analysis $^{9}$ of more than 450,000 breast examinations from 13 centres around the United States, combining tomosynthesis with digital mammography (which uses computers instead of X-ray film) found more cancers with fewer false positives than did mammography alone. But tomosynthesis delivers nearly twice as much radiation, says Etta Pisano, a radiologist at the University of South Carolina in Charleston. And comparative data are lacking. Pisano is planning a trial that would randomly assign 70,000 women to have either tomosynthesis or mammography to obtain the first accurate assessment of which technique helps women the most.

Further down the line, technologies in development include breast computed tomography scanners that are similar to tomosynthesis, but capture a more complete 3D image without as much radiation; phasecontrast imaging, which would show more detail of the interface between tumours and the surrounding tissue; and a bra that uses thermodynamic sensors to look for temperature fluctuations that might indicate signs of cancer. For now, the US Preventive Services Task Force has determined that more research is needed before it can recommend any of the emerging technologies. E. S.
American women living in nearly 550 counties that varied in mammography rates from less than $40 \%$ to nearly $80 \%$ they found that neither is happening ${ }^{7}$. Mammograms may do a good job at finding cancers, he says, but they do not seem to save many lives.

Mammography also carries risks. Besides the low-dose radiation from the $\mathrm{X}$-rays, women with abnormal results often go on to be scanned with even more powerful imaging machines, and sometimes this is followed by biopsies, chemotherapy, surgery and other painful or risky procedures that can cause infections or worse. Radiation therapy as a treatment for breast cancer increases deaths from heart disease by more than $25 \%$ and from lung cancer by nearly $80 \%$ - a big risk for a woman who may not need to take $\mathrm{it}^{3}$. The consequences are not just physical. Harris notes that being labelled as a 'cancer patient' can turn lives upside down. And although the emotional fallout has been poorly studied, interviews with women suggest that worrisome mammogram results are common sources of anxiety, intrusive thoughts, insomnia and other kinds of distress that can endure for a lifetime, he says.

There are also financial concerns. In one study, researchers totalled the money spent on breast cancer in the United States between 2011 and 2013. Using data collected by a health insurer on more than 700,000 women ${ }^{8}$, the authors found that US\$4 billion was spent each year on care for breast cancer as a result of false positives and overdiagnosis, including extra X-rays and biopsies. "It is a lot of money and it gives you a sense that this is not a small problem," says co-author Kenneth Mandl, a biomedical informatics specialist at Harvard Medical School in Boston, Massachusetts.

Meanwhile, a strong narrative of breast cancer survivorship endures, partly because it is impossible to know after treatment ends whether it was needed in the first place. "That is the screening paradox," says Gøtzsche. "The more healthy women you give an overdiagnosis to, the more they will tend to be happy because they think, 'Screening saved my life."'

It is an enduring irony that plagues the daily decisions women make about their health. "I believe mammography helps a few women," says Welch. "But it's a very few and it comes with tremendous human costs."

Emily Sohn is a freelance journalist living in Minneapolis, Minnesota.

1. Miller, A. B. et al. Br. Med. J. 348, g366 (2014)

2. Independent UK Panel on Breast Cancer Screening. Lancet 380, 1778-1786 (2012)

3. Gøtzsche, P. C. \& Nielsen, M. Cochrane Database Syst. Rev. 19, CD001877 (2011).

4. Harris, R., Yeatts, J. \& Kinsinger, L. Prev. Med. 53, 108-114 (2011)

5. Jørgensen, K. J., Zahl, P.-H. \& Gøtzsche, P. C. BMC Women's Health 9, 36 (2009).

6. Bleyer, A. \& Welch, G. N. Engl. J. Med. 367, 1998-2005 (2012)

7. Harding, C. et al. JAMA Intern. Med. 175, 1483 1489 (2015).

8. Ong, M.-S. \& Mandl, K. D. Health Aff. 34, 576-583 (2015).

9. Friedewald, S. M. et al. J. Am. Med. Assoc. 311 2499-2507 (2014). 